\title{
New fossil Procercopidae (Hemiptera: Cicadomorpha) from the Middle Jurassic of Daohugou, Inner Mongolia, China
}

\author{
Jun CHEN ${ }^{1}$, Bo WANG ${ }^{2,3}$, Haichun ZHANG ${ }^{2}$, XIAOLI WANG $^{1}$ and XIAOTING ZHENG ${ }^{1}$ \\ ${ }^{1}$ Institute of Geology and Paleontology, Linyi University, Shuangling Rd., Linyi 276000, China; e-mails: rubiscada@yahoo.com; \\ wangxiaoli@lyu.edu.cn; gsw@lyu.edu.cn \\ ${ }^{2}$ State Key Laboratory of Palaeobiology and Stratigraphy, Nanjing Institute of Geology and Palaeontology, East Beijing Rd., \\ Nanjing 210008, China; e-mails: savantwang@gmail.com; hczhang@nigpas.ac.cn \\ ${ }^{3}$ Steinmann Institute, University of Bonn, 53115 Bonn, Germany
}

Key words. Hemiptera, Cicadomorpha, Procercopidae, Anthoscytina, new species, fossil, Middle Jurassic, Daohugou

\begin{abstract}
Anthoscytina Hong, 1983 is the largest genus within the Mesozoic Procercopidae, the stem group of the superfamily Cercopoidea. Herein, we describe two new species from the Middle Jurassic of Daohugou, northeast China. Anthoscytina brevineura Chen, Wang \& Zhang, sp. n. and Anthoscytina elegans Chen, Wang \& Zhang, sp. n. are established on the basis of new well-preserved fossils. Although these two new species are very similar, some stable differences in tegminal venation and colour patterns confirm their species status. Sinotettegarcta longa Hong, 1986 is transferred to Anthoscytina, and to avoid secondary homonymy, a new name Anthoscytina hongi Chen, Wang \& Zhang, nom. n. is proposed for that species. In addition, Anthoscytina aphthosa Ren, Yin \& Dou, 1998 and Anthoscytina macula Hu, Yao \& Ren, 2014 are transferred from Anthoscytina to Stellularis Chen, Yao \& Ren, 2015.
\end{abstract}

\section{INTRODUCTION}

The Cercopoidea Leach, 1815 is one of the most speciose superfamilies of Cicadomorpha, with nearly 3000 described species attributed to five modern families and three extinct families from the Mesozoic (Hamilton, 2001; Dietrich, 2002; Hu et al., 2012; Wang et al., 2012). Most fossil and extant cercopoids are small insects, usually shorter than 13 mm (Hong, 1983; Wang \& Zhang, 2009). Adult cercopoids are commonly called froghoppers because they look like tiny frogs and are very adept at jumping (Burrows, 2003). Their nymphs, known as spittlebugs, cover themselves with foaming spittle to provide protection from predation, parasitism and desiccation (Hamilton, 1982; Li et al., 2013).

The family Procercopidae, as the earliest cercopoid group, is recorded from the Early Jurassic to Early Cretaceous in Germany, Russia, Central Asia, Southeast Asia and China. Anthoscytina Hong, 1983, the largest genus within the Procercopidae, was erected on the basis of a complete tegmen from the Middle Jurassic of Beipiao, Liaoning in China (Hong, 1983). It was previously referred to the family Scytinopteridae Handlirsch, 1906 and later transferred to the Procercopidae (Shcherbakov, 1988). The tegminal lengths reported for species of Anthoscytina range from 10 $\mathrm{mm}$ to $15 \mathrm{~mm}$.

Very recently the present authors collected some new giant procercopids from Daohugou in Northeast China, of which some are assigned to the genus Anthoscytina. We report herein on two of these species with tegmens of around $20 \mathrm{~mm}$ in length.

\section{MATERIAL AND METHODS}

The fossils were collected from the Middle Jurassic Jiulongshan Formation in Daohugou Village, Ningcheng County, Chifeng
City, Inner Mongolia, China. The palaeoenvironmental reconstructions indicate a humid and warm-temperate climate in the Middle Jurassic in the Daohugou area (Ren \& Krzeminski, 2002; Wang et al., 2013). These deposits are well-known for yielding a highly diverse array of insects (e.g., Hou et al., 2012a, b; Yan \& Wang, 2010; Chen J. et al., 2014), including very large numbers of cercopoids (Wang \& Zhang, 2009; Wang et al., 2012; Li et al., 2013). All the material collected is housed in the Shandong Tianyu Museum of Nature (STMN) at Pingyi, Shandong, China.

The fossils were examined using a stereomicroscope (Zeiss SteREO Discovery V8). Photographs were taken using a Nikon D800 digital camera. Line drawings were prepared with two image-editing pieces of software (CorelDraw 12.0 and Adobe Photoshop CS3). In the line drawings, faintly seen and hypothesized regions are indicated by dotted lines, the edges of missing regions indicated by thin solid lines. All measurements were made using software Image J 1.42q (Wayne Rasband; National Institute of Health, USA).

Currently there is no consensus over the interpretation of vein nomenclature in Cicadomorpha (Wang et al., 2009). Herein, we tentatively follow Nel et al. (2012) and Bourgoin et al. (2014) with slight modifications.

\section{SYSTEMATIC PALAEONTOLOGY}

Order Hemiptera Linnaeus, 1758

Suborder Cicadomorpha Evans, 1946

Superfamily Cercopoidea Leach, 1815

Family Procercopidae Handlirsch, 1906

\section{Genus Anthoscytina Hong, 1983}

Type species. Anthoscytina longa Hong, 1983; Haifanggou Formation, Beipao City, Liaoning, China; Middle Jurassic.

Species included. A. longa Hong, 1983; A. reducta (Becker-Migdisova, 1949); A. liugouensis (Hong, 1983); A. daica Shcherbakov, 1988; A. parallelica Ren, Lu \& Guo, 1995; A. trinervus (Ren, Lu \& Guo, 1995); A. pustulosus (Ren, Lu \& Guo 1995); A. perpetua Li, Shih \& Ren, 2013; A. hongi Chen, Wang \& 

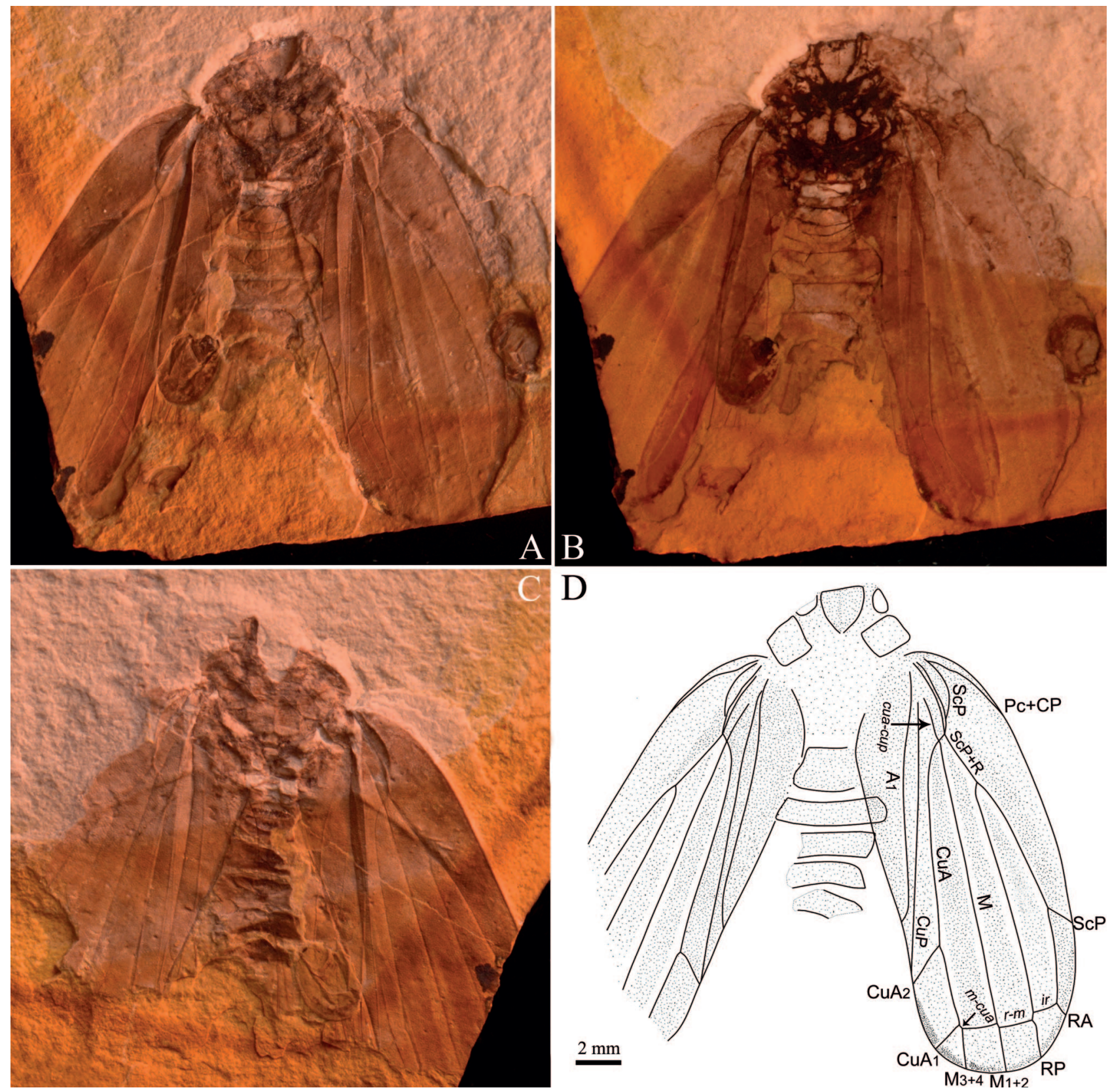

Fig. 1. Holotype of Anthoscytina brevineura Chen, Wang \& Zhang, sp. n. A - photograph of part of STMH 48-1782a; B - photograph of part of STMH 48-1782a, under alcohol; C - photograph of the counterpart of STMH 48-1782b; D - illustration based on STMH 48-1782a. All to scale.

Zhang, nom. n.; A. brevineura Chen, Wang \& Zhang, sp. n.; and A. elegans Chen, Wang \& Zhang, sp. $\mathrm{n}$.

Revised diagnosis. Fore femur robust, hind tibia long and slender, with a short lateral spine; Ovipositor short; tegmen with vein $\mathrm{R}$ bifurcating near basal 1/3 wing length; RA simple or multi-branched; RP simple; $M$ with at most 3 branches; CuA branching basal of or at the same level as the branch in M; cross vein im absent; hind wing with vein RA and RP simple, $\mathrm{M}$ and $\mathrm{CuA}$ two-branched.

Remarks. Shcherbakov (1988) revised the generic diagnosis and transferred Cycloscytina reducta BeckerMigdisova, 1949 to this genus. He suggested that Paracicadella Hong, 1983 and Paracicadella beipiaoensis Hong, 1983 are junior synonyms of Anthoscytina Hong,
1983 and A. longa Hong, 1983, respectively. Furthermore, Wang et al. (2012) treated Mesocercopis Hong, 1983 and Sinotettegarcta Hong, 1986 as synonyms of Anthoscytina Hong, 1983, but did not mention the validity of both Mesocercopis longa Hong, 1983 and Sinotettegarcta longa Hong, 1986. For M. longa, the most important characters at the specific level are not included in the original description, so it is impossible to determine its species status until the type specimen is re-examined. Sinotettegarcta longa is similar to A. longa in terms of the pattern in the venation and size, but distinctly differs from the latter in that on the tegmen $\mathrm{R}$ is multi-branched and $\mathrm{M}$ branches close to the apex of the wing. 

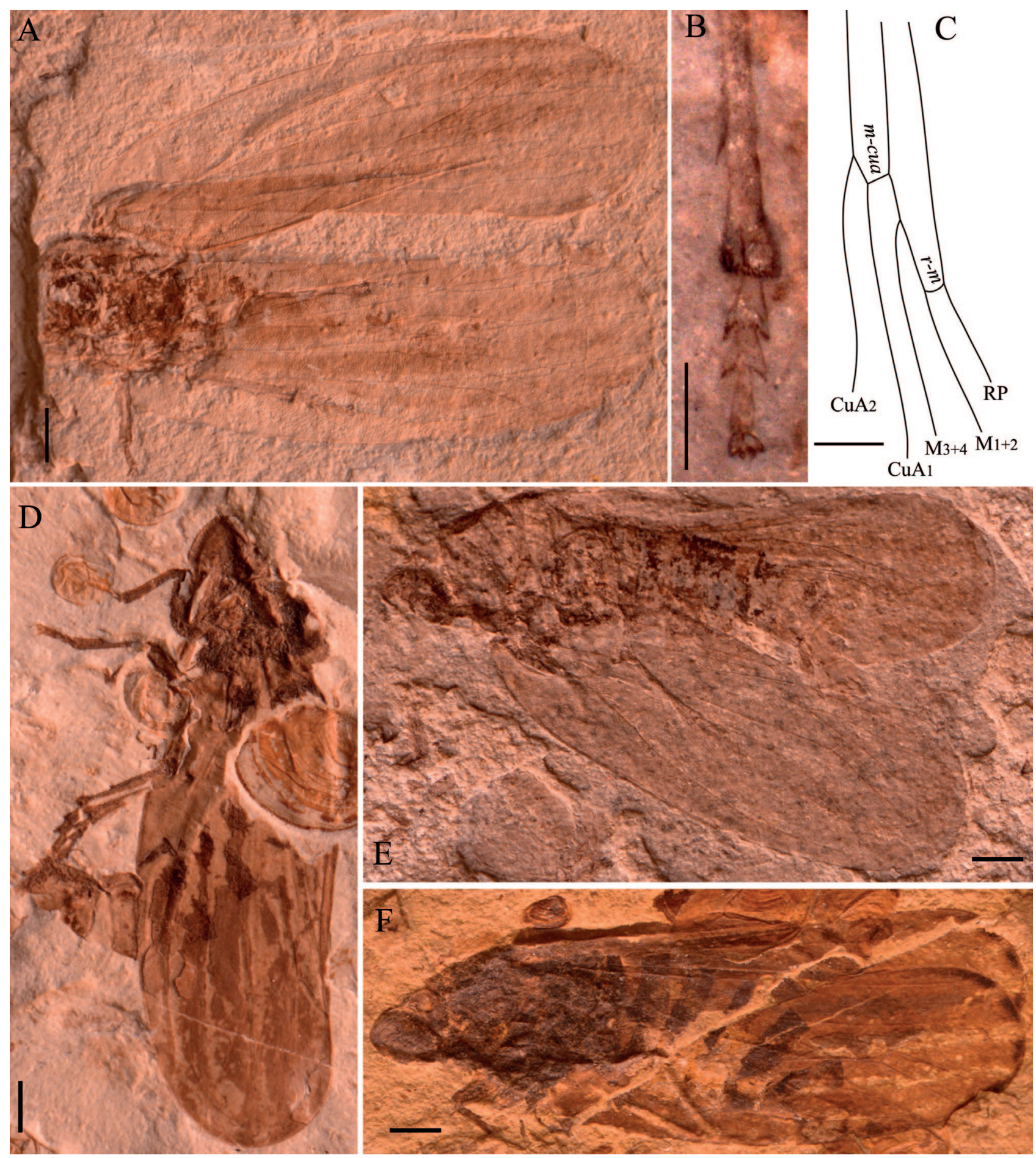

Fig. 2. Paratypes of Anthoscytina brevineura Chen, Wang \& Zhang, sp. n. A-STMH 48-1783; B - hind leg of 48-1783, under alcohol; C - line drawing of hind wing of 48-1783; D - STMH 48-1784a; E - STMH 48-1785; F - STMH 48-1786a. Scale bars $=2$ mm.

Anthoscytina hongi Chen, Wang \& Zhang, nom. n.

Anthoscytina hongi Chen, Wang \& Zhang, nom. n. for Anthoscytina longa (Hong, 1986: 14-15, Fig. 5, Pl. II: 3) comb. n. (described as Sinotettegarcta longa), a junior secondary homonym of Anthoscytina longa Hong, 1983: 61-62, Fig. 47, P1. 10: 3.

Etymology. The specific epithet is named after Youchong Hong who described the species.

Remarks. This species is very similar to the type species of Anthoscytina, but differs from the latter in having a tegmen with cross veins $i r$ and $r-m$ almost at the same level. It is similar to A. daica and A. parallelica in having a tegmen with a multi-branched $\mathrm{R}$ and differs in its $\mathrm{M}_{1+2}$ and $\mathrm{M}_{3+4}$ are longitudinal and nearly parallel.

\section{Anthoscytina brevineura Chen, Wang \& Zhang, sp. n.}

(Figs 1, 2)

Etymology. The specific epithet is derived from the Latin "brevis" (meaning short) and "neurus" (meaning vein), which refers to the extremely short cross vein $m$-cua.

Holotype. STMN48-1782, sex unknown, adult in ventral view with tegmen preserved. 

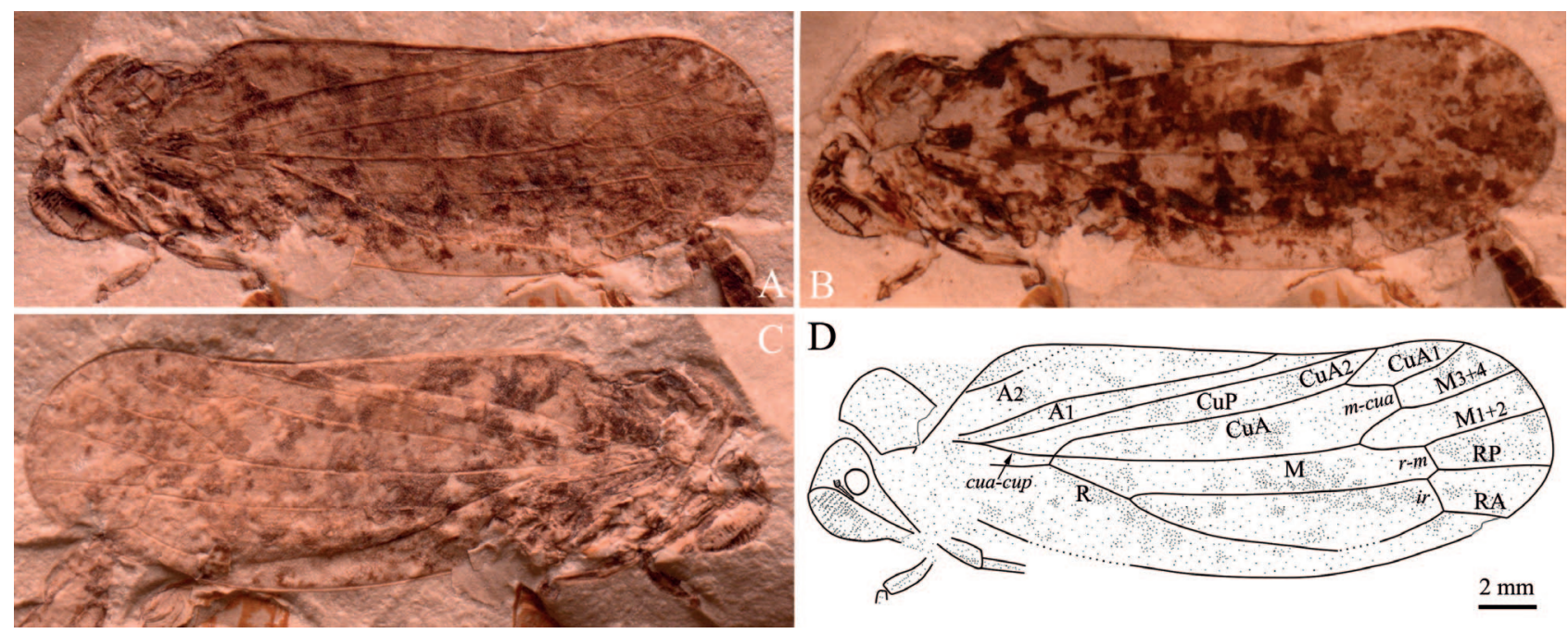

Fig. 3. Holotype of Anthoscytina elegans Chen, Wang \& Zhang, sp. n. A - photograph of part of STMH 48-1787a; B - photograph of part of STMH 48-1787a, under alcohol; C - photograph of the counterpart of STMH 48-1787b; D - illustration based on STMH 48-1787a. All to scale.

Type locality. Daohugou Village, Shantou Township, Ningcheng County, Inner Mongolia, China.

Type horizon. Jiulongshan Formation, Middle Jurassic.

Paratypes. STMN48-1783, sex unknown, adult in dorsal view with tegmen and hind wing preserved; STMN48-1784, adult female in lateral aspect with tegmen preserved; STMN48-1785, adult male in lateral aspect with tegmen and hind wing preserved; STMN48-1786, sex unknown, adult in lateral aspect with tegmen preserved.

Diagnosis. Body large. Tegmen broad; membrane tinged with longitudinal stripes, and apical margin darkly stained; RA simple, connected with $\mathrm{M}_{1+2}$ by cross vein $r-m$ just distal of junction with cross vein ir; stem $\mathrm{M}$ branching into $M_{1+2}$ and $M_{3+4}$ near base at 0.9 wing length; $M_{1+2}$ short, transverse; $\mathrm{M}_{3+4}$ vertical, rectangular at junction with cross vein $m$-сua, and then transverse; cross vein $m$-cua extremely short; $\mathrm{CuA}_{1}$ parallel to $\mathrm{M}$, geniculate at junction with cross vein $m$-cua, and then running subparallel to
$\mathrm{CuA}_{2} ; \mathrm{CuA}_{2}$ short and oblique. Hind wing, $\mathrm{M}_{1+2}$ and $\mathrm{CuA}$ nearly straight.

Description. Body 21.0-23.2 mm long including tegmen in repose (Figs 1, 2A, D-F). Postclypeus swollen, about $2.0 \mathrm{~mm}$ long, with weak oblique grooves and a distinct median groove. Compound eyes large, nearly round (Figs 1, 2F). Pronotum well-developed, approximately 3.0 $\mathrm{mm}$ wide. Fore femur extremely strong, about $2.5 \mathrm{~mm}$ long and $0.8 \mathrm{~mm}$ wide; fore tibia about $2.4 \mathrm{~mm}$ long (Fig 2D). Middle femur slenderer than fore femur, approximately $0.6 \mathrm{~mm}$ wide; middle tibia slightly longer than fore tibia, approximately $2.7 \mathrm{~mm}$ long; middle tarsus about $1.0 \mathrm{~mm}$ long, with three tarsomeres; apical tarsomere longer than mid tarsomere and basitarsomere; two claws and an arolium visible (Figs 2A, D). Hind tibia slender, about $3.5 \mathrm{~mm}$ long, with a short lateral spine $2 / 3$ along its length and two rows of tiny teeth apically; hind tibia about $1.8 \mathrm{~mm}$ long; basitarsomere and mid tarsomere similar in shape, and

TABLE 1. Morphometric data of tegmina of the specimens included in this study. Abbreviations: $\mathrm{L}-$ length (mm); $\mathrm{W}-$ width (mm); $\mathrm{L} / \mathrm{W}$ - length/width ratio; $\mathrm{R}$ - branching position of vein $\mathrm{R}$ / tegmen length; $\mathrm{M}$ - branching position of vein $\mathrm{M}$ / tegmen length; CuAbranching position of vein $\mathrm{CuA} /$ tegmen length.

\begin{tabular}{lccccccc}
\hline \multirow{2}{*}{ Species } & \multirow{2}{*}{ Specimen } & \multicolumn{5}{c}{ Measurement } \\
\cline { 3 - 7 } & & $\mathrm{L}$ & $\mathrm{W}$ & $\mathrm{L} / \mathrm{W}$ & $\mathrm{R}$ & $\mathrm{M}$ & $\mathrm{CuA}$ \\
\hline \multirow{3}{*}{ Anthoscytina brevineura } & STMN48-1782 & 18.2 & 7.1 & 2.6 & 0.34 & 0.87 & 0.68 \\
& STMN48-1783 & 20.3 & 6.8 & 3.0 & 0.31 & 0.89 & 0.68 \\
& STMN48-1784 & 19.4 & 7.3 & 2.6 & 0.31 & - & 0.66 \\
& STMN48-1785 & 18.5 & 6.6 & 2.8 & 0.33 & - & 0.66 \\
& STMN48-1786 & 18.5 & 6.4 & 2.9 & - & - & 0.67 \\
\hline \multirow{3}{*}{ Anthoscytina elegans } & STMN48-1787 & 20.5 & 7.3 & 2.8 & 0.32 & 0.68 & 0.66 \\
& STMN48-1788 & 22.2 & 8.6 & 2.6 & 0.28 & 0.71 & 0.66 \\
& STMN48-1789 & 23.2 & 8.5 & 2.7 & 0.30 & 0.67 & 0.64 \\
& STMN48-1790 & 21.5 & 8.4 & 2.6 & 0.32 & 0.76 & 0.69 \\
& STMN48-1791 & 20.4 & 7.5 & 2.7 & 0.27 & 0.64 & 0.65 \\
& STMN48-1792 & 21.8 & 7.9 & 2.8 & - & 0.68 & 0.67 \\
& STMN48-1793 & 20.7 & - & - & 0.32 & 0.69 & - \\
& STMN48-1794 & 20.8 & 7.8 & 2.7 & 0.31 & 0.72 & 0.71 \\
& STMN48-1795 & 23.1 & 7.5 & 2.9 & 0.30 & 0.67 & 0.63 \\
& STMN48-1796 & 22.0 & 7.8 & 2.8 & 0.31 & 0.70 & 0.69 \\
\hline
\end{tabular}



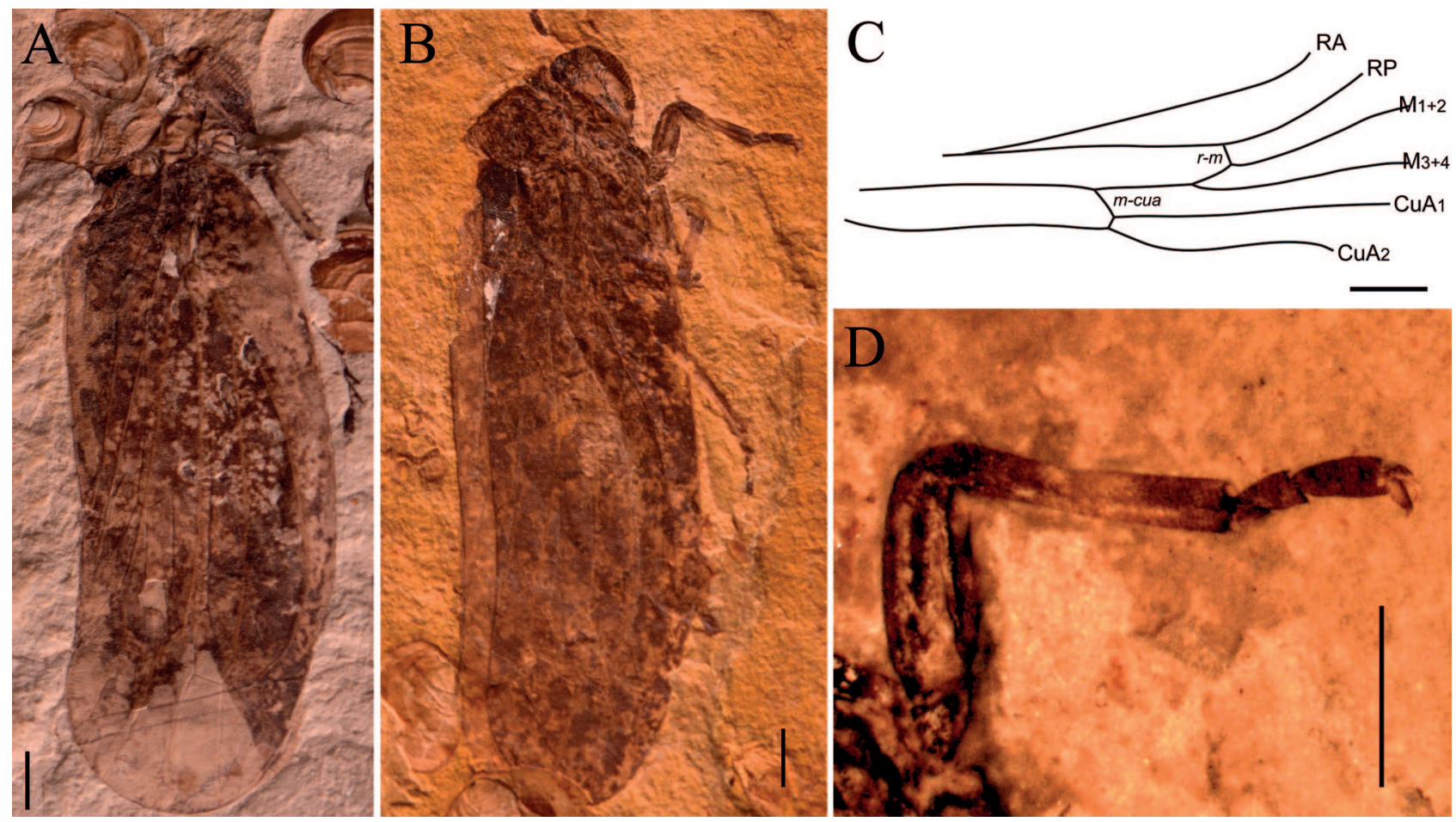

Fig. 4. Paratypes of Anthoscytina elegans Chen, Wang \& Zhang, sp. n. A - STMH 48-1788a; B - STMH 48-1789; C - line drawing of hind wing of STMH 48-1788; D - fore leg of STMH 48-1789b, under alcohol. Scale bars $=2 \mathrm{~mm}$.

with a row of tiny apical denticles; apical tarsomere long and slender, with two strong claws and a distinct arolium (Figs 2A, B, D). Ovipositor short, not extending beyond pygofer, slightly curved upwards (Fig 2D). Male genitalia well-developed; sclerotized genital plate visible; anal tube elongate, curved downwards in lateral view (Fig 2E).

Tegmen broad, 18.2-20.3 mm long and 6.4-7.3 mm wide, with length/width ratio from 2.6 to 3.0 (Figs 1, 2A, D-F; Table 1). Tegmen tinged with longitudinal stripes and apical margin darkly stained. Costal margin slightly arched. Posterior margin curved at about basal 0.18 wing length and then slightly recurved at the ending of vein $\mathrm{CuP}$. Apical margin rounded. $\mathrm{Pc}+\mathrm{CP}$ running to costal margin and $\mathrm{ScP}$ running to and fusing with $\mathrm{R}+\mathrm{M}+\mathrm{CuA}$. $\mathrm{ScP}+\mathrm{R}$ separating from $\mathrm{ScP}+\mathrm{R}+\mathrm{M}$ in basal 0.2 region of wing length, and bifurcating into $\mathrm{ScP}+\mathrm{RA}$ and RP in basal $1 / 3$ wing length. RA simple, separating from ScP+RA, and then connected with RP by nearly vertical cross vein $i r$ just before the end. RP simple, almost straight, connected with $\mathrm{M}_{1+2}$ by cross vein $r-m$ just distal of junction with cross vein ir. Stem $M$ subparallel to RP, and branching into $M_{1+2}$ and $\mathrm{M}_{3+4}$ near basal 0.9 wing length. $\mathrm{M}_{1+2}$ short, longitudinal. $\mathrm{M}_{3+4}$ perpendicular to stem $\mathrm{M}$, rectangular at junction with cross vein $m$-cua, and then longitudinal. Cross vein m-cua extremely short. Stem $\mathrm{CuA}$ bifurcating into $\mathrm{CuA}$ and $\mathrm{CuA}_{2}$ in basal 2/3 region of wing length. $\mathrm{CuA}_{1}$ parallel to $\mathrm{M}$, geniculate at junction with cross vein $m$-cua, and then running subparallel to $\mathrm{CuA}_{2}$. $\mathrm{CuA}_{2}$ short and oblique. $\mathrm{CuA}$ connected to $\mathrm{CuP}$ by long cross vein cua-cup at departure from $\mathrm{M}+\mathrm{CuA}$. CuP long and straight. $\mathrm{A}_{1}$ sinuous, strongly curved apically.
Hind wing partly preserved (Figs 2A, C, E-F). RP long, curved at junction with cross vein $r-m$. Stem $\mathrm{M}$ straight, slightly curved at junction with cross vein $m$-cua, then running subparallel to RP before branching into $\mathrm{M}_{1+2}$ and MP. $\mathrm{M}_{1+2}$ nearly straight, connected with RP by cross vein $r-m$. Stem $\mathrm{CuA}$ straight, two-branched. $\mathrm{CuA}_{1}$ connected to $\mathrm{M}$ by cross vein $m$-cua. $\mathrm{CuA}_{2}$ sinuous.

Remarks. Based on the tegminal venation, this new species can be distinguished from other species within the $A n$ thoscytina in having an extremely short cross vein $m$-cua. This new species is similar to A. aphthosa in having cross veins $i r, r-m$, and $m$-cua extremely close to wing apex, but the new species is much larger in size and has a tegmen with vein $\mathrm{M}$ two-branched.

\section{Anthoscytina elegans Chen, Wang \& Zhang, sp. n.}

(Figs 3-5)

Etymology. The specific epithet is derived from the Latin "elegans" (meaning elegant), and refers to this species' beautiful shape.

Holotype. STMN48-1787, sex unknown, adult in lateral aspect with tegmen preserved.

Type locality. Daohugou Village, Shantou Township, Ningcheng County, Inner Mongolia, China.

Type horizon. Jiulongshan Formation, Middle Jurassic.

Paratypes. STMN48-1788, sex unknown, adult in lateral aspect with tegmen and hind wing preserved; STMN48-1789, sex unknown, adult in lateral aspect with tegmen preserved; STMN48-1790, adult male in lateral aspect with tegmen preserved; STMN48-1791, adult male in lateral aspect with tegmen preserved; STMN48-1792, sex unknown, adult in lateral aspect with tegmen preserved; STMN48-1793, adult male in lateral aspect with tegmen preserved; STMN48-1794, adult male in lateral aspect with tegmen preserved; STMN48-1795, sex unknown, 

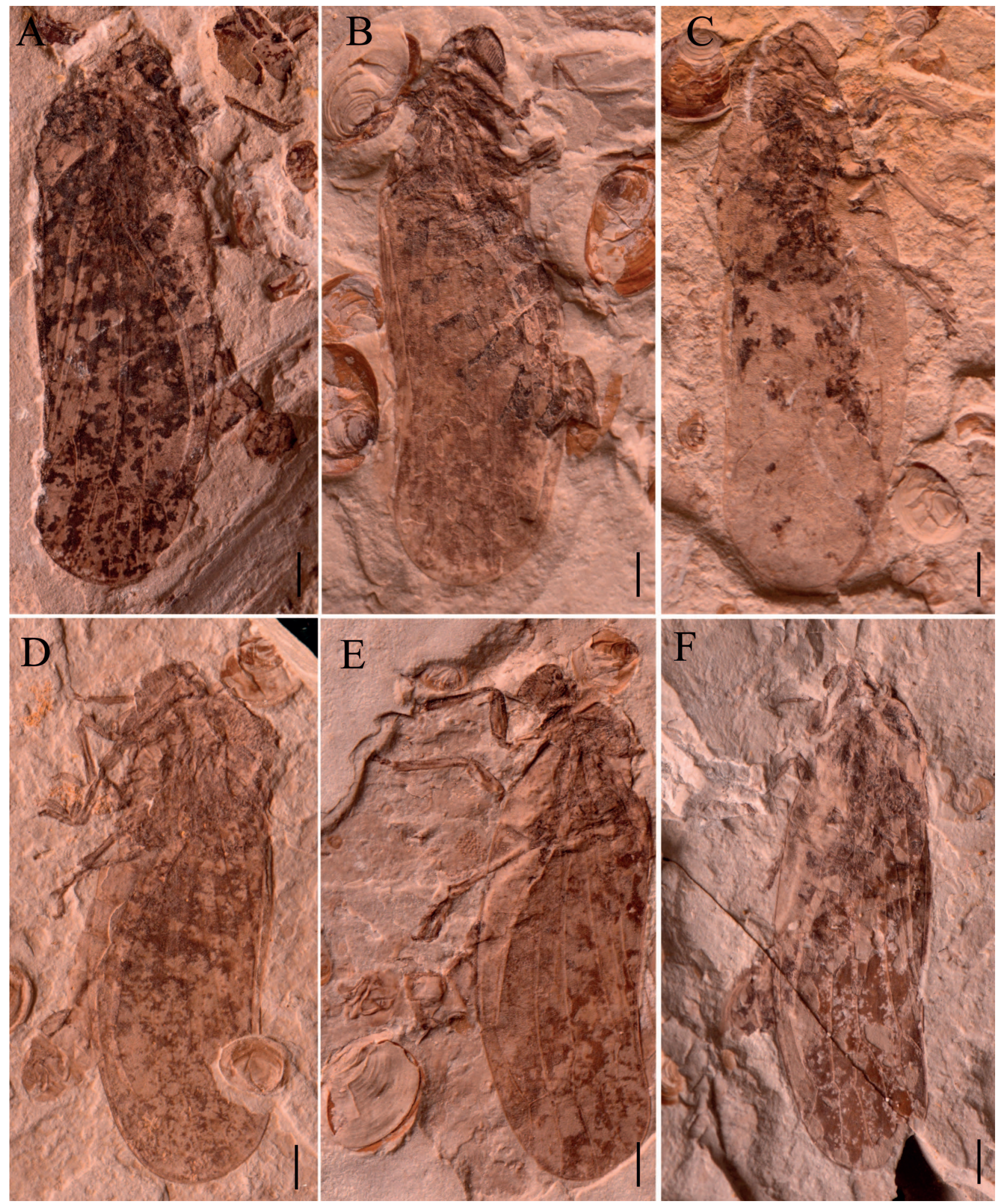

Fig. 5. Paratypes of Anthoscytina elegans Chen, Wang \& Zhang, sp. n. A - STMH 48-1790; B - STMH 48-1791a; C - STMH 481792; D - STMH 48-1793; E - STMH 48-1794a; F - STMH 48-1796. Scale bars $=2 \mathrm{~mm}$.

adult in lateral aspect with tegmen preserved; STMN48-1796, adult female in lateral aspect with tegmen preserved.

Diagnosis. Body large. Tegmen broad; membrane with dark and irregular patches; stem $M$ branching into $M_{1+2}$ and $\mathrm{M}_{3+4}$ near basal 0.7 wing length; $\mathrm{M}_{1+2}$ nearly as long as MP.
Cross vein $m$-cua basal of or at the same level as cross vein $r-m ; \mathrm{CuA}_{1}$ about two to three times as long as $\mathrm{CuA}_{2}$. Hind wing, RP curved just beyond junction with cross vein $r-m$; $\mathrm{CuA}_{1}$ connected with $\mathrm{M}$ by cross vein $m$-cua just beyond departure from $\mathrm{CuA}$ and then almost straight. 
Description. Body 23.1-25.8 mm long including tegmen in repose (Figs 3, 4A, B, 5). Postclypeus swollen, about $3.0 \mathrm{~mm}$ long, with oblique grooves and a distinct median groove. Compound eyes large, nearly round (Figs 3, 5A). Antennal length about $0.8 \mathrm{~mm}$; scape and pedicel thick; flagellum aristiform, with segments invisible (Figs 3B, D). Pronotum well-developed, with width about $3.0 \mathrm{~mm}$. Fore femur extremely strong, about $2.5 \mathrm{~mm}$ long and nearly 1.0 $\mathrm{mm}$ wide; fore tibia about $3.0 \mathrm{~mm}$ long, fore tarsus about $1.5 \mathrm{~mm}$ long, with three tarsomeres; basitarsomere very short; apical tarsomere longer than mid tarsomere; two claws and an arolium visible (Figs 4B, D, 5C, E). Middle femur and tibia almost as long as fore femur and tibia respectively; middle femur slenderer than fore femur; middle tarsus slight shorter than fore tarsus, with three tarsomeres; apical tarsomere longer than mid tarsomere and basitarsomere; two claws and an arolium visible (Figs 5C, E). Hind tibia slender, with a short lateral spine on basal $2 / 3$ of its length and two rows of tiny teeth apically; hind tarsus about $2.0 \mathrm{~mm}$ long, with three tarsomeres visible; basitarsomere and mid tarsomere of similar shape, and with a row of tiny apical denticles (Figs 5C-E). Male genitalia well-developed; sclerotized genital plate visible in lateral view; anal tube elongate, strongly curved (Figs 5A, D, E). Ovipositor short, just extending beyond pygofer, slightly curved upwards (Fig 5F).

Tegmen broad, 20.4-23.2 $\mathrm{mm}$ long and 7.3-8.6 mm wide, with length/width ratio from 2.6 to 2.9 (Figs 3, 4A, $\mathrm{B}$, 5; Table 1). Tegmen with dark and irregular patches (Figs 3, 4A, B, 5A). Costal margin slightly arched. Posterior margin of basal 1/6 wing length curved and then recurving at the ending of vein CuP. Apical margin rounded. $\mathrm{Pc}+\mathrm{CP}$ running to costal margin and $\mathrm{ScP}$ running to and fusing with $\mathrm{R}+\mathrm{M}+\mathrm{CuA}$. $\mathrm{ScP}+\mathrm{R}$ bifurcating into $\mathrm{ScP}+\mathrm{RA}$ and RP at about basal 0.3 wing length. RA simple, separating from $\mathrm{ScP}+\mathrm{RA}$, and then connected with $\mathrm{RP}$ by cross vein ir. RP simple, almost straight, connected with $\mathrm{M}_{1+2}$ by cross vein $r-m$ just distal of junction with cross vein ir. Stem M subparallel to RP, and branching into $\mathrm{M}_{1+2}$ and $\mathrm{M}_{3+4}$ near basal 0.7 wing length. $\mathrm{M}_{1+2}$ nearly as long as MP. Cross vein $m$-cua basal of or at the same level as cross vein $r-m$. Stem $\mathrm{CuA}$ bifurcating into $\mathrm{CuA}_{1}$ and $\mathrm{CuA}_{2}$ in basal $2 / 3$ of wing length. $\mathrm{CuA}_{1}$ two to three times as long as $\mathrm{CuA}_{2}$. $\mathrm{CuA}$ connected to $\mathrm{CuP}$ by long cross vein cua-cup at departure from $\mathrm{M}+\mathrm{CuA}$. CuP long and straight. $\mathrm{A}_{1}$ nearly straight, slightly curved apically. $\mathrm{A}_{2}$ short, oblique.

Hind wing partly preserved (Figs 4A, C). RA curved apically. RP long, curved just beyond junction with cross vein $r-m$. Stem M nearly straight, subparallel to RP, and twobranched. $\mathrm{M}_{1+2}$ sinuous, curved at junction with cross vein $r-m$. Stem $\mathrm{CuA}$ slightly curved, two-branched. $\mathrm{CuA}_{1}$ connected with $\mathrm{M}$ by cross vein $m$-cua just beyond departure from $\mathrm{CuA}$ and then straight. $\mathrm{CuA}_{2}$ sinuous.

Remarks. Anthoscytina elegans Chen, Wang \& Zhang, sp. n. is very much bigger than the other species in the genus Anthoscytina. This new species resembles $A$. brevineura Chen, Wang \& Zhang, sp. n., which is similar in size, venation patterns on tegmen and hind wing, and other body structures, but they differ in the length of cross vein $m$-cua, the branching position of stem $\mathrm{M}$ and colour patterns on tegmen.

\section{DISCUSSION}

There is considerable intra-specific or even intra-individual variation in the venation of some procercopids (e.g., Ansorge, 1996; Ren et al., 1998). Both of the two new species reported herein were discovered in the same horizon at the same locality (Jiulongshan Formation in Daohugou Village), are similar in size, tegminal venation and other body structures (Figs 1 and 2; Table 1), which indicates a close relationship. However, there are also some stable differences in venation and the colour patterns on the tegmen, which confirm that they are independent biological species. In addition, both species are represented by both male and female specimens, which exclude the possibility that the morphological variation is sexual dimorphism.

To date, thirteen species are assigned to Anthoscytina (Becker-Migdisova, 1949; Hong, 1983, 1986; Shcherbakov, 1988; Ren, 1995; Ren et al., 1998; Li et al., 2013; Hu et al., 2014; Chen D. et al., 2015; this study), making it the largest genus of Procercopidae. These species are known from the Early Jurassic to Early Cretaceous in Russia, Central Asia and China, and show an extremely high diversity in tegminal venation as well as other body structures, indicating that this large genus is possibly the result of a poorly defined combination of characters, which might not validly reflect a natural subdivision (i.e., a polyphyletic group).

Ren et al. (1998) erected Anthoscytina aphthosa based on several compression fossils from the Lower Cretaceous in northern China, and the species is very special in having tegmen and hind wing with vein $\mathrm{M}$ simple (vs. tegmen with $\mathrm{M}$ with at least two branches and hind wing with $\mathrm{M}$ two-branched in other procercopids). Anthoscytina macula $\mathrm{Hu}$, Yao \& Ren, 2014, collected from contemporaneous strata at a nearby locality, is very similar to A. aphthosa in having similar wing venation. Chen D. et al. (2015) report a new procercopid with vein $\mathrm{M}$ on tegmen and hind wing simple on the basis of one fossil specimen collected at the same locality as $A$. aphthosa, but put this species into a new genus Stellularis. The unusual wing venation suggests that these three species are obviously different from the type species of Anthoscytina, and A. aphthosa and A. macula, and should be transferred to the genus Stellularis.

Li et al. (2013) report a pair of copulating procercopids, and erected a new species Anthoscytina perpetua. The abundant fossil material described by Li et al. (2013) indicate that the ovipositor of $A$. perpetua is short, not exceeding anal tube. A. daica Shcherbakov, 1988, A. brevineura Chen, Wang \& Zhang, sp. n.; and A. elegans Chen, Wang \& Zhang, sp. n. also have short ovipositors. However, the ovipositors of $A$. aphthosa and $S$. longirostris are extremely long, exceeding the tip of the tegmina (Ren et al., 1998; Chen D. et al., 2015). This difference in the length of the ovipositors further confirms that Anthoscytina and Stellularis are two independent genera and $A$. aphthosa and $A$. macula should be transferred to Stellularis. 
The family Procercopidae is widely accepted as the stem group of cercopiods, which includes the ancestors of modern Cercopoidea (Shcherbakov \& Popov, 2002; Wang et al., 2012). Tegmen and hind wing with vein $M$ unbranched are apomorphic characters for extant cercopoids. These characters are also shared by Stellularis from the Early Cretaceous in Northeastern China (Ren et al., 1998; Hu et al., 2014; Chen D. et al., 2015), suggesting that this genus possibly represents a transitional form between Procercopidae and recent Cercopoidea. By the mid-Creaceous, the remaining procercopids became extinct and modern cercopoids (Aphrophoridae and Cercopidae) appeared (Shcherbakov \& Popov, 2002).

ACKNOWLEDGEMENTS. The authors are extremely grateful to J. Zhang for his constructive comments on an earlier version of this manuscript. We also express our heartfelt thanks to P. Štys and two anonymous reviewers who provided many constructive comments that undoubtedly improved this manuscript. The present study was supported by a grant from the National Natural Science Foundation of China (41372014) and the Natural Scientific Foundation of Shandong Province (ZR2013DQ017). B. Wang was also supported by a Research Fellowship awarded by the Alexander von Humboldt Foundation.

\section{REFERENCES}

ANSORGE J. 1996: Insekten aus dem Oberen Lias von Grimmen (Vorpommern, Norddeutschland). - Neue Paläontol. Abh. 2: $1-132$.

Becker-Migdisova E.E. 1949: Mesozoic Homoptera of Middle Asia. - Tr. Paleontol. Inst. Akad. Nauk SSSR 22: 1-68 [in Russian].

Bourgoin T., Wang R., Asche M., Hoch H., Soulier-Perkins A., Stroinski A., Yap S. \& Szwedo J. 2014: From micropterism to hyperpterism: recognition strategy and standardized homology-driven terminology of the forewing venation patterns in planthoppers (Hemiptera: Fulgoromorpha). - Zoomorphology DOI 10.1007/s00435-014-0243-6.

Burrows M. 2003: Biomechanics: froghopper insects leap to new heights. - Nature 424: 509.

Chen D., Yao Y. \& Ren D. 2015: A new species of fossil Procercopidae (Hemiptera, Cicadomorpha) from the Lower Cretaceous of Northeastern China. - Cretaceous Res. 52: 402-406.

Chen J., Wang B., Zhang H. \& Wang X. 2014: A remarkable new genus of Tettigarctidae (Insecta, Hemiptera, Cicadoidea) from the Middle Jurassic of northeastern China. - Zootaxa 3764: $581-586$.

Dietrich C.H. 2002: Evolution of Cicadomorpha (Insecta, Hemiptera). - Denisia 4: 155-170.

Hamilton K.G.A. 1982: The Insects and Arachnids of Canada. Part 10. The Spittlebugs of Canada. Homoptera: Cercopidae. Agriculture Canada, Ottawa, 102 pp.

Hamilton K.G.A. 2001: A new family of froghoppers from the American tropics (Hemiptera: Cercopoidea: Epipygidae). Biodiversity 2: 15-21.

Hong Y. 1983: Middle Jurassic Fossil Insects in North China. Geological Publishing House, Beijing, 148 pp. [in Chinese, English abstr.].
Hong Y. 1986: New fossil insects of Haifanggou Formation, Liaoning Province. - J. Changchun Coll. Geol. 4: 10-16 [in Chinese, English abstr.].

Hou W., Yao Y. \& Ren D. 2012a: The review of Cercopoidea (Hemiptera) fossils. - J. Environ. Entomol. 234: 483-496.

Hou W., Yao Y., Zhang W. \& Ren D. 2012b: The earliest fossil flower bugs (Heteroptera: Cimicomorpha: Cimicoidea: Vetanthocoridae) from the Middle Jurassic of Inner Mongolia, China. - Eur. J. Entomol. 109: 281-288.

Hou W., Yao Y. \& Ren D. 2014: New fossil Procercopidae (Hemiptera, Cicadomorpha) from the Early Cretaceous of Northeastern China. - Acta Geol. Sin. 88: 725-729.

Li S., Shit C., Wang C., Pang H. \& Ren D. 2013: Forever love: The hitherto earliest record of copulating insects from the Middle Jurassic of China. - PLOS ONE 8: e78188.

Nel A., Prokop J., Nel P., Grandcolas P., Huang D., Roques P., Guilbert E., Dostál O. \& Szwedo J. 2012: Traits and evolution of wing venation pattern in paraneopteran insects. - J. Morph. 273: 480-506.

Ren D. 1995: Systematic Palaeontology. Fossil insects. In Ren D., Lu L., Guo Z. \& Ji S. (eds): Fauna and Stratigraphy of Jurassic-Cretaceous in Beijing and the Adjacent Areas. Seismic Publishing House, Beijing, pp. 47-120 [in Chinese, English abstr.].

Ren D. \& KrZeminski W. 2002: Eoptychopteridae (Diptera) from the Middle Jurassic of China. - Ann. Zool. 52: 207-210.

Ren D., YIN J. \& Dou W. 1998: New planthoppers and froghoppers from the Late Jurassic of northeast China. - Acta Zool. Sin. 23: 281-288.

Shcherbakov D.E. 1988: New cicadas (Cicadina) from the Late Mesozoic of Transbaikalia. - Paleontol. Zh. 4: 55-66.

Shcherbakov D.E. \& Popov Y.A. 2002: Superorder Cimicidea Laicharting, 1781 order Hemiptera Linné, 1758. The bugs, cicadas, plantlice, scale insects, etc. In Rasnitsyn A.P. \& Quicke D.L.J. (eds): History of Insects. Kluwer, Dordrecht, pp. 152155.

WANG B. \& Zhang H. 2009: A remarkable new genus of Procercopidae (Hemiptera: Cercopoidea) from the Middle Jurassic of China. - C. R. Palevol. 8: 389-394.

Wang B., Zhang H. \& Szwedo J. 2009: Jurassic Palaeontinidae from China and the higher systematics of Palaeontinoidea (Insecta: Hemiptera: Cicadomorpha). — Palaeontology 52: 53-64.

Wang B., Szwedo J. \& Zhang H. 2012: New Jurassic Cercopoidea from China and their evolutionary significance (Insecta: Hemiptera). - Palaeontology 55: 1223-1243.

Wang B., Zhang H., Jarzembowski E.A., Fang Y. \& Zheng D. 2013: Taphonomic variability of fossil insects: a biostratinomic study of Palaeontinidae and Tettigarctidae (Insecta: Hemiptera) from the Jurassic Daohugou Lagerstätte. - Palaios 28: 233242.

YAN E.V. \& WANG B. 2010: A new genus of elateriform beetles (Coleoptera, Polyphaga) from the Jurassic of Daohugou, China. - Paleontol. J. 44: 297-302.

Received July 14, 2014; revised and accepted December 2, 2014 Prepublished online February 16, 2015 